\title{
Inflammation of the respiratory tract is associated with CCL28 and CCR10 expression in a murine model of allergic asthma
}

\author{
Karen English ${ }^{\mathrm{a}}$, Claire Brady ${ }^{\mathrm{a}}$, Paul Corcoran ${ }^{\mathrm{a}}$, Joseph P. Cassidy ${ }^{\mathrm{b}}$, Bernard P. Mahon ${ }^{\mathrm{a}, *}$ \\ ${ }^{a}$ Mucosal Immunology Laboratory, Institute of Immunology, NUI Maynooth, Co. Kildare, Ireland \\ ${ }^{\mathrm{b}}$ Department of Veterinary Pathology, University College Dublin, Ireland
}

Received 22 March 2005; received in revised form 23 September 2005; accepted 23 September 2005

Available online 21 October 2005

\begin{abstract}
Mouse models and in vitro cell culture were used to examine airway expression of the mucosal chemokine CCL28. Low levels of constitutively expressed mRNA were observed in transformed murine epithelial cells, but high levels could be induced by stimulation. Cytokines that signal through NF- $\mathrm{B}$, including IL-1 $\beta$ and TNF- $\alpha$ or via JAK-STAT pathway including oncostatin M induced CCL28 in airway epithelial cells in vitro. Immunohistochemistry of murine airway tissue revealed that constitutive expression of CCL28 protein in vivo was low and not ubiquitous. However, abundant expression was detected in epithelia and lymphoid aggregates following allergic sensitization and challenge with ovalbumin. This was accompanied by increased detection of cells expressing CCR10 protein and mRNA in inflamed airways. Taken together, these data support a role for CCL28 in contributing to allergen driven airway pathologies, show that proinflammatory cytokines can induce this signal and suggest a role for CCR10 expressing cells in airway inflammation.
\end{abstract}

(C) 2005 Elsevier B.V. All rights reserved.

Keywords: CCL28; IL-1ß; Oncostatin M; CCR10; Eosinophil

\section{Introduction}

CC chemokine ligand 28 (CCL28) is a CC $(\beta)$ chemokine $[1,2]$ encoded on human chromosome $5 \mathrm{q}$ (mouse chromosome 13) outside the regular $\mathrm{CC}$ chemokine cluster located at human chromosome 17. It is encoded by four exons, separated by large introns $[1,2]$. Human and mouse CCL28 are highly conserved sharing $83 \%$ amino acid identity and $76 \%$ identity at the nucleic acid level [2]. Despite a putative role in mucosal inflammation [3-6], there have been few studies of CCL28 expression. Immunohistochemistry and laser capture microdissection have indicated that epithelial cells from colon and salivary tissue expressed CCL28 [1] and immuno-electron microscopy showed CCL28 localized to secretory granules within epithelial cells and at mucosal sites $[3,6]$. CCL28 mRNA has been detected in human trachea and bronchus-associated epithelial cells by Northern blot analysis [1]. Expression of murine CCL28 is less well characterized, but CCL28 has been shown in the testis, and at lower levels in kidney and brain [2]. These data suggest that

\footnotetext{
* Corresponding author. Tel.: +3531708 3835; fax: +3531 1086337 .

E-mail address: bpmahon@may.ie (B.P. Mahon).
}

CCL28 has both a homeostatic role and an involvement in the inflammatory responses of the mucosal immune system [2].

Asthma is a chronic disease of the airways characterized by inflammation, remodelling and airway hyper-responsiveness [7]. Epithelial shedding, airway wall thickening, elevated IgE levels and mucus hyper-secretion are other hallmark features associated with the disease [7]. Many cell types, including eosinophils, mast cells and CD4+ T helper type 2 (Th2) lymphocytes, play a role in asthmatic airway inflammation [8]. As with most inflammatory conditions, CC chemokines and pro-inflammatory cytokines have been implicated in the pathogenesis [9], for example, IL- $1 \beta$ and TNF- $\alpha$, signal via NF- $\kappa$ B activation and are elevated in asthma [10]. Both cytokines are secreted by activated monocyte/macrophages and have been characterized as triggers for chemokine expression at sites of inflammation [11]. Likewise, oncostatin M (OSM), a member of the IL-6 family can induce CCL11 (eotaxin) linked to airway pathology [12]. Until very recently, little was known about CCL28 induction in humans or in murine models of human disease $[13,14]$.

The CC chemokine receptors CCR 3 and CCR 10 are known to recognize CCL28 [1]. Th2 cells and effector cells such as basophils, mast cells and eosinophils express CCR3, and a major 
role for CCL28 in the trafficking of CCR3+ eosinophils has been proposed [14]. CCR3 engagement is thought to be responsible for the recruitment of basophils, mast cells and eosinophils to inflammatory sites, driven by CCL11 (eotaxin) $[15,16]$. CCL28 can also support chemotaxis of blood eosinophils via this receptor [1]. The pathogenic role of eosinophils in asthma pathogenesis is not clear but recent work demonstrates a role for eosinophils in the early events associated with asthma induction $[17,18]$. The interaction of CCL28 with CCR3 expressed by Th2 cells and eosinophils strongly suggests that this novel chemokine has a role in asthmatic inflammation [6,13], however, the interaction between CCL28 and CCR10 remains less explored $[2,19]$.

In the present study, we set out to examine the role of CCL28 in a murine model of allergic airway inflammation. We demonstrate that CCL28 is constitutively but not ubiquitously expressed at low levels by murine airway epithelial cells in vitro and in vivo. We show that CCL28 expression is upregulated in vitro by the inflammatory cytokines IL- $1 \beta$ and TNF- $\alpha$, as well as by OSM. Furthermore, this study demonstrates that whilst CCL28 is expressed at low levels in healthy airway epithelium, it is abundantly expressed in the inflamed airways of sensitized mice and this is associated with an increase of CCR 10 expression at this mucosal site.

\section{Materials and methods}

\subsection{Animals}

Six- to eight-week-old female BALB/c (Harlan, UK) mice were used for experiments under the guidelines of the Irish Department of Health and the research ethics committee of the National University of Ireland Maynooth.

\subsection{Cell lines}

Cultured murine lung epithelial cells (MLE-12) were allowed to adhere to the matrix of the culture plate overnight, before $6 \mathrm{~h}$ stimulation with IL-1 $\beta$, TNF- $\alpha$ or OSM (R\&D Systems, Abingdon, UK). RNA was then isolated from these cells for use in RT-PCR.

\subsection{Quantitative real time RT-PCR}

RNA from MLE-12 cells was extracted using Tri Reagent ${ }^{\mathrm{TM}}$ (Molecular Research Center, Cincinnati, $\mathrm{OH}$ ) according to the manufacturer's instructions. cDNA was analyzed for the expression of murine CCL28, CCR3 or CCR10 by fluorogenic 5'nuclease PCR assay (MJ Research Inc., Waltham, MA). Briefly, cDNA $(1.0 \mu \mathrm{g})$ were amplified in the presence of $\mathrm{SYBR}^{\circledR}$ Green PCR mastermix, forward and reverse primer sequences were as previously described $[3,6]$. As an internal positive control GAPDH-specific forward and reverse primers were used in a similar reaction. Accumulation of gene-specific PCR products was measured continuously by means of fluorescence detection over 40 cycles. Standard curves for CCL28 expression were generated amplifying 10 -fold serial dilutions of known quantities of
CCL28, CCR3 or CCR10 plasmid DNA. Quantification of target gene expression was obtained using sequence detector system software (MJ Research Inc., Waltham, MA).

\subsection{Cytokine measurement}

Concentrations of IL-4, IL-5, and IL-13 from culture supernatants were assessed after 24,48 and $72 \mathrm{~h}$ culture by ELISA (BD Pharmingen, San Diego, CA). Cytokine concentrations were calculated by comparison with known cytokine standards as previously described [8], all determinations were made in triplicate, results are presented as mean cytokine concentration ( \pm S.E.M.).

\subsection{Ova sensitization}

Mice were sensitized to OVA or sham sensitized with endotoxin free PBS as previously described [8]. Six- to eight-weekold female BALB/c mice ( $n=5$ per group minimum, but in some cases $n=8)$ (OVA) were sensitized by i.p. injection of $100 \mu \mathrm{g}$ Ova (Grade V; Aldrich-Sigma Chemical Co., Dorset, UK) emulsified in 2\% Alhydrogel $^{\circledR}$ adjuvant (Superfos Biosector, Sweden) at 0 and $14 \mathrm{~d}$. Control groups (Ctrl) received saline alone (i.p.). On day 14, sensitized mice also received $50 \mu \mathrm{g}$ Ova or saline intranasally. On 25,26 and $27 \mathrm{~d}$, sensitized mice received $50 \mu \mathrm{g}$ OVA or saline intra-nasally. On $28 \mathrm{~d}$, mice were assessed for airway hyper-reactivity by plethysmography, and then sacrificed. Airway tissue (trachea, bronchi and lungs) was removed and stored in RNALater ${ }^{\mathrm{TM}}$ (Ambion Inc., Austin, TX) as previously described for detection of CCL28 and CCR 10 mRNA, or processed for histology and immunohistochemistry. All experiments were performed at least twice.

\subsection{Immunohistochemistry}

CCL28-specific reagents were developed from two rabbits immunized with the following peptide sequence: CGHTTRKHRTRGTHRHEASR conjugated to BSA. Likewise, CCR10 -specific reagents were developed from rabbits immunized with the following peptide sequence: RRCRLIFPESLTQTVKGC conjugated to BSA. Immunized rabbits were boosted four times at two weekly intervals. Batches of preand post-immune sera were tested by dot blot analysis and ELISA (Biosource International, Nivelles, Belgium). Batches of sera displaying strong specific CCL28 or CCR10 reactivity but no binding by irrelevant or related antigens were affinity purified against the immunogen. Airway tissue was prepared as previously described [8]. Tissue was unmasked in tri-sodium citrate solution (BDH, Cork, Ireland) and blocked with normal goat serum (Vector Laboratories Ltd., Peterborough, UK). After overnight incubation with pre-immune or immune sera sections were treated with biotin-labelled goat anti-rabbit $\operatorname{IgG}$ (Vector Laboratories) and the substrate. Counter-staining was performed as previously described [8].

\subsection{Whole-body plethysmography}

Airway responsiveness was assessed by methacholine (MCh) induced airflow obstruction from conscious mice using whole- 
body plethysmography (Buxco Electronics, Sharon, CT) as previously described [8]. Pulmonary airflow obstruction was measured by enhanced pause $(\mathrm{PenH})$, a value determined from the ratio of expiratory time and relaxation time to peak expiratory flow and peak inspiratory flow, a surrogate of airway responsiveness. Measurements were obtained after exposure of mice for 3 mins to PBS (baseline) followed by incremental doses $(1.0-50 \mathrm{mg} / \mathrm{ml})$ of $\mathrm{MCh}$ delivered by aerosol.

\subsection{Respiratory tract histology}

Animals ( $n$ between 5 and 8 per group per experiment) were sacrificed and lungs were removed, fixed in a paraformaldehyde/lysine/periodate fixative, paraffin embedded, sectioned and stained using haematoxylin and eosin, Discombes (identification of eosinophils), Alcian blue (identification of mucus), PAS (assessment of basement membrane thickness) and Van Gieson (identification of fibrosis) methods as previously described $[8,20,21]$. Histopathological changes evident were graded according to a semi-quantitative scoring system as mild, moderate or severe by two researchers without prior knowledge of the treatment group using a previously established scoring system. All experiments were performed at least twice.

\subsection{Statistical methods}

Results are expressed as the mean \pm S.E.M. of the indicated number of animals. A Student's $t$-test was used to determine significance among the groups. A value of $p<0.05$ was considered significant. Analyses were performed using Graph-Pad Prism ${ }^{\mathrm{TM}}$ software (GraphPad, San Diego, CA).

\section{Results}

\subsection{CCL28 mRNA is constitutively present in airway epithelial-like cells but is upregulated by inflammatory stimuli}

In order to identify the signals involved in controlling CCL28 expression, quantitative RT-PCR was performed on cDNA isolated from the airway epithelial-like cell line MLE-12. CCL28 mRNA was constitutively expressed at low levels in cultured MLE-12 cells (Fig. 1A-C). However, the expression of many $\mathrm{CC}$ chemokines is controlled by cytokines induced by microbial insult. The influence of IL-1 $\beta$, TNF- $\alpha$ and OSM upon expression of murine CCL28 mRNA was therefore examined. TNF- $\alpha$ or IL-1 $\beta$ stimulation of MLE-12 cells significantly increased the mean level of CCL28 mRNA $(p<0.005$ and $p<0.005$ respectively)(Fig. 1A and B). Cells remained viable throughout the period of culture and there was no significant induction of apoptosis in these experiments. Murine OSM at $1-50 \mathrm{ng} / \mathrm{ml}$ induced high levels of CCL28 expression in MLE-12 cells (Fig. 1C). Interestingly OSM signals via a type I cytokine receptor pathway involving a common gp130 subunit that activates the JAK-Stat pathway. Stimulation of MLE-12 cells with IL-1 $\beta$, TNF- $\alpha$ or OSM did not induce the Th2 cytokines IL-4, IL-5
TNF-1 $\alpha$

(A)

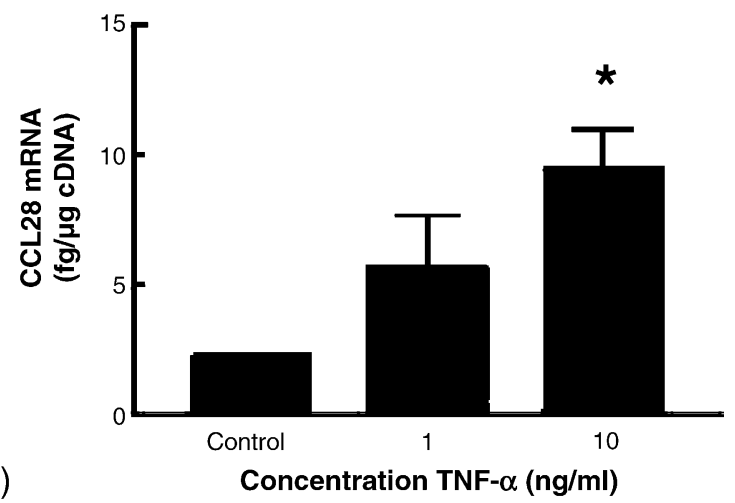

IL-1 $\beta$

(B)

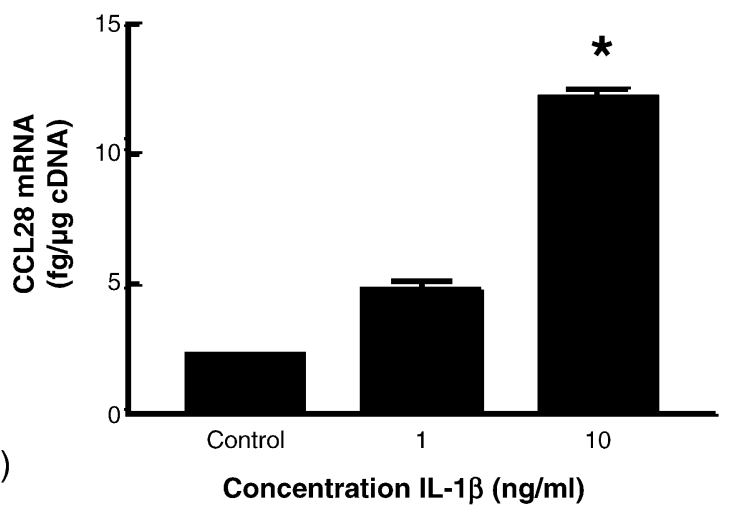

Oncostation M

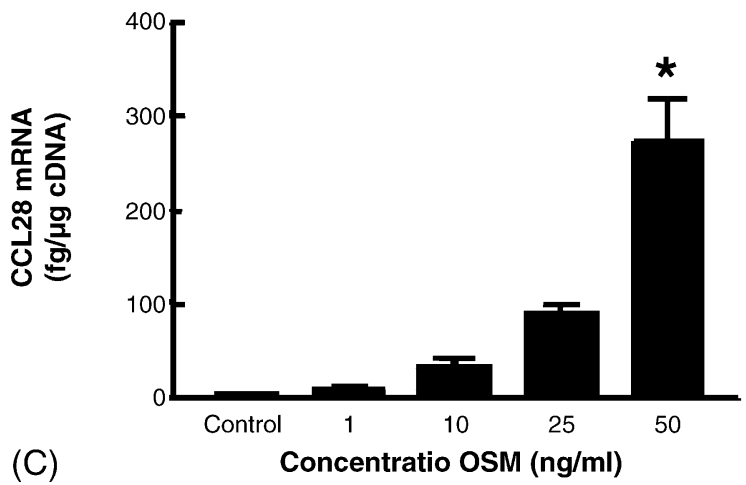

Fig. 1. Levels of CCL28 mRNA were determined by quantitative real time PCR from MLE-12 cells unstimulated or stimulated with varying concentrations of TNF- $\alpha$ (A), IL-1 $\beta$ (B) or OSM (C). Results shown are mean ( \pm S.E.M.) of three determinations from a representative experiment performed at least three times; asterisk $(*)$ indicates statistical significance from unstimulated control, $p<0.005$.

or IL-13 at $24 \mathrm{~h}$ (Fig. $2 \mathrm{~A}-\mathrm{C}$ ) or at $48 \mathrm{~h}$ or $72 \mathrm{~h}$ culture (data not shown). Taken together, these results suggest that high level CCL28 expression by airway epithelial cells can be induced by direct signalling through transduction pathways usually associated with microbial insult (IL-1 $\beta / \mathrm{TNF}-\alpha$, OSM). 

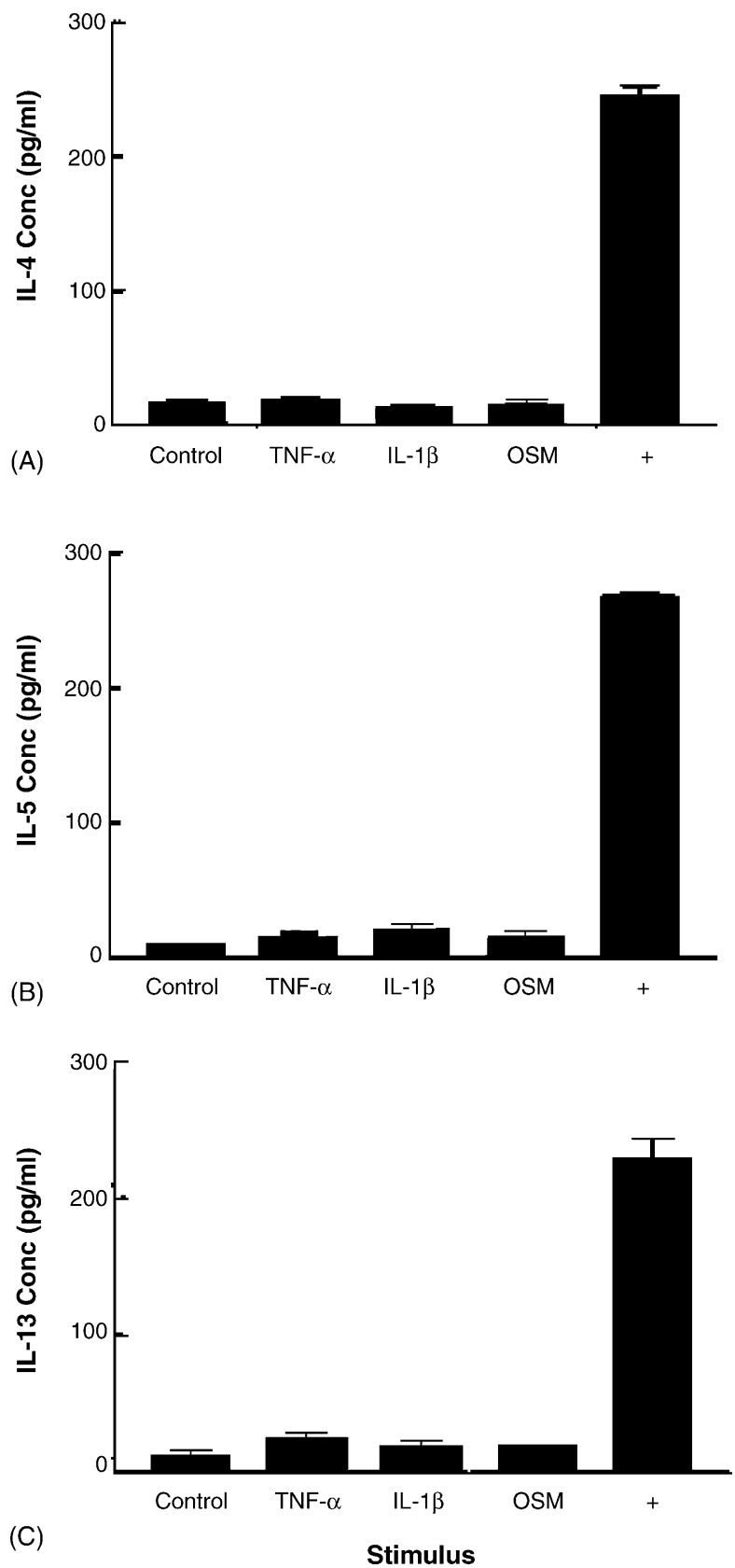

Fig. 2. IL-4 (A), IL-5 (B) and IL-13 (C) are not induced from MLE-12 cells. MLE-12 cells were stimulated with either medium control (open bar), TNF$\alpha(10 \mathrm{ng} / \mathrm{ml}), \mathrm{IL}-1 \beta(10 \mathrm{ng} / \mathrm{ml})$ or OSM $(50 \mathrm{ng} / \mathrm{ml})$ and supernatants assayed at $24 \mathrm{~h}$ for the presence of cytokine by commercial ELISA. Recombinant cytokines (solid) bar are shown for comparison as a positive control. Experiment shown is representative of two independent studies, assayed in triplicate, presented as the mean concentration of cytokine detected \pm S.E.M.

\subsection{Expression of CCL28 protein is limited in the normal murine airways but is extensive in a murine model of allergic inflammation}

Expression of chemokine mRNA does not always correlate well with protein production and secretion. Therefore, CCL28 expression in normal healthy murine airways was measured by immunohistochemistry of fixed tissue. Non-specific labelling was not observed with control reagents (Fig. 3A and B); however constitutive CCL28 production could be detected in untreated control mice or mice exposed to endotoxin-free PBS (Fig. 3C and D). Expression was not universal but tended to occur in patches of epithelial cells in the conducting airways (Fig. 3D). In contrast to control mice (Fig. 3D), mice that had been sensitized to OVA mice expressed abundant CCL28 (Fig. 3E-G). CCL28 expression was predominantly within epithelia of the conducting airways and was associated with the typical eosinophil infiltrate (Fig. 3E-G, and Table 1) previously reported [8]. Expression was also detected in lymphoid aggregations associated with inflammation in OVA sensitized mice (Fig. 3H). Peri-airway inflammation, assessed in terms of overall degree and absolute numbers, revealed increased infiltrating eosinophils, neutrophils and plasma cells in line with our previous observations (Table 1) as well as an increase in surrogate measures of airway hyperreactivity (Fig. 4) [8]. Although the affinity purified reagents described above showed no non-specific labeling, it was possible that the CCL28 anti-serum used was detecting an unidentified chemokine induced under similar conditions. The level of CCL28 mRNA present in control and OVA sensitized lung tissue was therefore determined by quantitative RT-PCR. Levels of CCL28 mRNA were significantly greater in sensitized compared to controls (Fig. 5A). Taken together, these data indicate that CCL28 is present in sensitized airways and suggests that it plays a role in airway diseases in which eosinophilic infiltrates are a pathological feature [22].

\subsection{CCR10+ cells and levels of CCR10 mRNA are elevated in inflamed airways}

The chemokine receptors CCR 3 and CCR10 have been shown as functional receptors for CCL28 in vitro. CCR3 expression in OVA sensitized mice has been previously characterized; we therefore examined CCR 10 expression in the airways of mice sensitized to OVA. Using affinity purified rabbit anti-CCR10 reagents, CCR10 expression could not be detected in the airways of control mice, nor was non-specific labeling detected (Fig. 6), however, as with similar models of CCR3+ infiltration [23], cells expressing CCR10 were readily detected in the airway epithelium (Fig. 6F and H) and BALT (Fig. 6D) of OVAsensitized mice. However, there was a possibility that rather than CCR10, affinity purified polyclonal reagents were detecting a closely related ligand. Therefore, CCR10-specific quantitative PCR of cDNA derived from lung tissue was performed. Significantly more CCR10-specific mRNA could be detected in the lungs of OVA sensitized mice compared to controls (Fig. 5B), suggesting that the increased expression seen in OVA sensitized tissue reflects an increased influx of CCR10+ cells (Fig. 6D, F and $\mathrm{H})$.

\section{Discussion}

In this study we show that CCL28 is constitutively expressed at low levels in transformed murine epithelial cells. CCL28 expression can be upregulated by various proinflammatory cytokines signalling via both the NF-кB (IL-1 $\beta$ and TNF- $\alpha$ ) and JAK-STAT (OSM) pathways [24]. Immunohistochemistry 

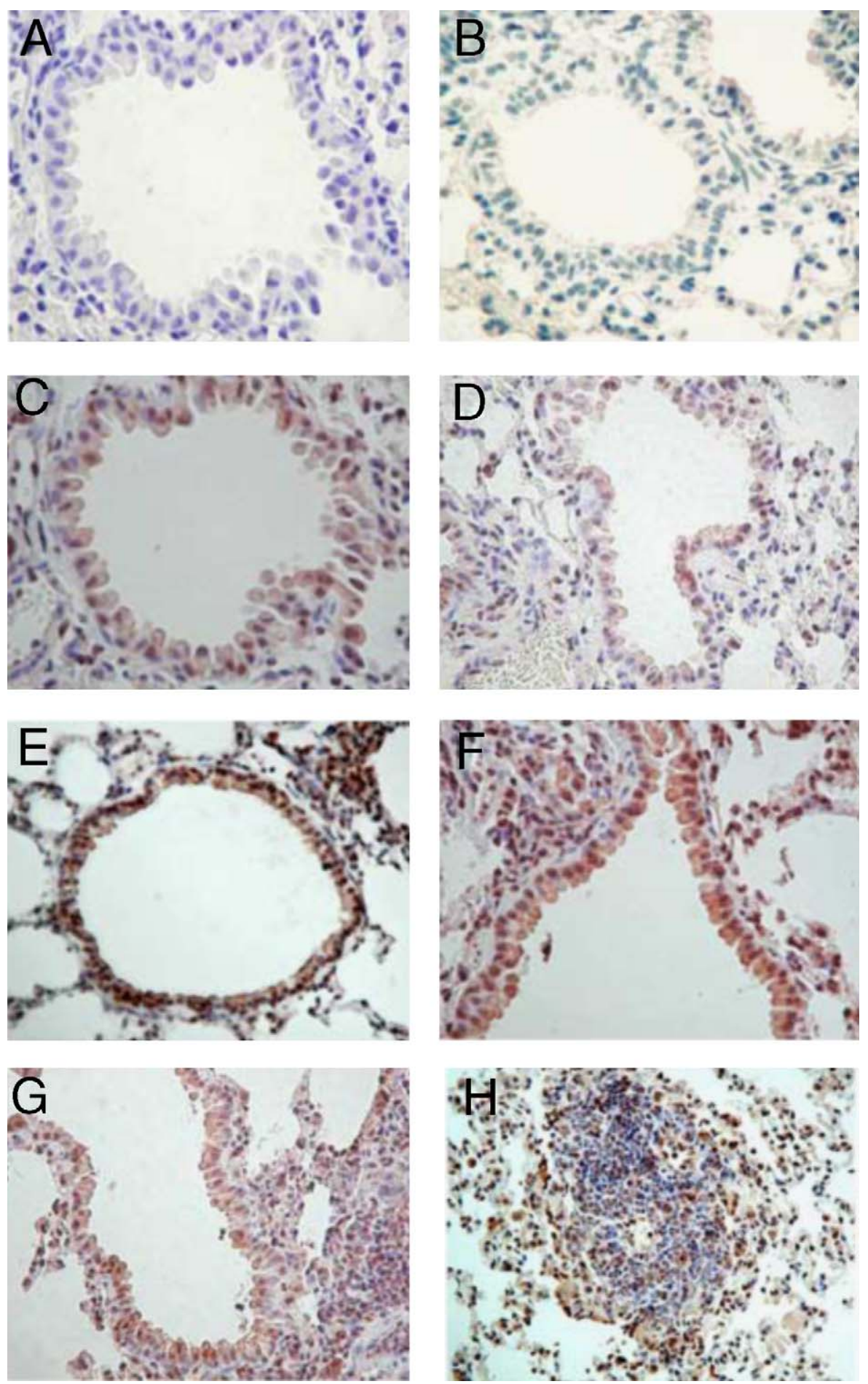

Fig. 3. In vivo expression of CCL28 revealed by immunohistochemistry. Mice ( $n=8$ per group) were either unsensitized (A), sham sensitized with endotoxin-free PBS (B and D) or sensitized to OVA (E-H). Lung/trachea sections were assayed using an irrelevant polyclonal rabbit serum (A), pre-immune rabbit serum (B) or a rabbit anti-mouse CCL28 serum $(\mathrm{C}-\mathrm{H})$. All sections were probed using biotinylated goat anti-rabbit IgG, streptavidin conjugated horse radish peroxidase using 3,3'-diaminobenzidine tetrahydrochloride as substrate. All sections were counterstained with haematoxylin. Original magnification $\times 400$. Observations are representative sections from at least two experiments where $n=5$ in each case.

revealed that constitutive expression of CCL28 protein in normal murine airways was not ubiquitous, but using the OVA model of airway hyper-reactivity, we demonstrate that CCL28 protein and mRNA is abundantly expressed in allergen-sensitized airways. Furthermore, we provide evidence that cells expressing
CCR10, a receptor for CCL28, are present in the airways of OVA sensitized mice.

Cytokines, such as TNF- $\alpha$ and IL-1 $\beta$ are known to be involved in airway inflammation. Both of these cytokines are elevated in asthma and can signal via activation of NF-кB [25]. 
Table 1

Pathological score of airway inflammation

\begin{tabular}{|c|c|c|c|c|c|c|c|}
\hline Group & Hyperplasia of airway epithelium & Smooth muscle hypertrophy & \multicolumn{5}{|c|}{ Peri-airway/vascular inflammation ${ }^{a}$} \\
\hline Control & - & - & - & - & - & - & - \\
\hline
\end{tabular}

A semi-quantitative score (- absent, + mild, ++ moderate, +++ severe) was assigned to features of airway pathology observed according to previously described criteria.

a Peri-airway/vascular inflammation was assessed in terms of overall degree and of numbers of infiltrating eosinophils (Eo), neutrophils (PMN), lymphocytes, plasma cells and macrophages (L), and the presence of macrophage giant cells (M) in inflammatory exudates within the surrounding alveolar spaces. Results are representative from histological examination of eight mice $(n=8)$ scored independently by two observers.

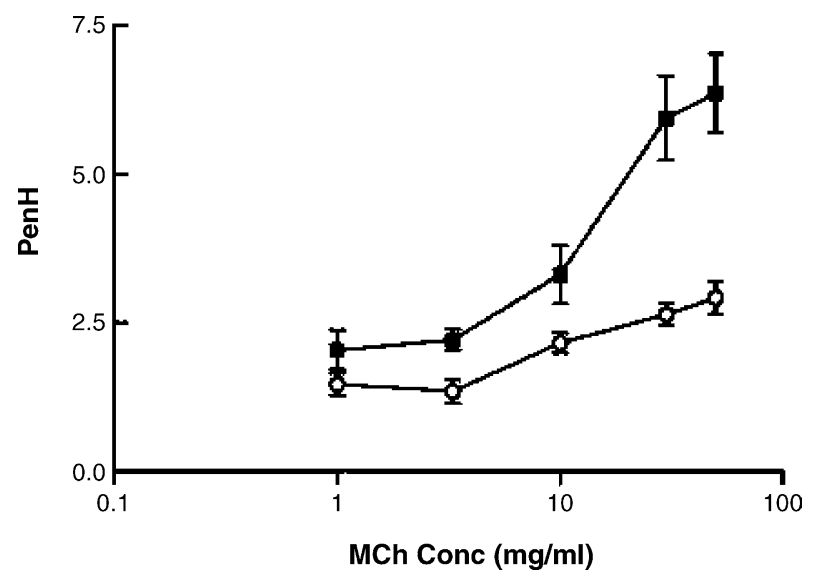

Fig. 4. OVA sensitization induces airway hyper-reactivity in response to increasing concentrations of inhaled methacholine (MCh). Hyper-reactivity was measured by whole-body plethysmography in unsensitized (control) or sensitized (OVA) mice. Results are expressed as mean enhanced pause (PenH) \pm S.E.M. from a representative of two experiments ( $n=8$ mice per group).

IL-1 $\beta$ and TNF- $\alpha$ upregulate expression of a range of proinflammatory genes that in turn influence aspects of the asthmatic response such as airway smooth muscle responsiveness [25]. The present findings show for the first time that IL- $1 \beta$ can induce CCL28 expression by epithelial cells and supports the data of Ogawa et al who showed TNF- $\alpha$ and IL- $1 \alpha$ induced CCL28. The functional activity of the chemokine produced under these conditions will require the development of novel sensitive CCL28 bioassays. The paradox whereby Th1 inducing stimuli including infection can exacerbate $\mathrm{Th} 2$ driven airway pathologies has been extensively documented $[8,20,21,26]$. The induction of CCL28 by IL- $1 \beta$ is important because it provides another link through which pro-inflammatory microbial insult (often considered to be Th1 driven) can exacerbate asthmatic or allergic responses, considered as Th 2 driven pathologies. One prediction arising out of this hypothesis is that bacterial inflammation of the airways would induce IL-1 $\beta$ and a co-ordinated upregulation of CCL28 expression, it would also be predicted that successful respiratory pathogens have evolved adversarial strategies to counter the effects of CCL28. The observation that CCL28 has direct anti-microbial activity is also consistent with a model in which airway induction is coupled to the appearance of IL- $1 \beta$ and TNF$\alpha$, as early mediators of inflammation [6,27] and suggests that studies of CCL28 during airway infection would be informative.

We show for the first time that CCL28 can be induced at high level independently of the NF-кB pathway by OSM [24]. OSM is an IL-6 like cytokine that regulates eosinophilic infiltration in part through CCL11 (eotaxin), induces the proliferation of smooth muscle cells, and also alters the balance between matrix metalloproteinases and their tissue inhibitors, again characteristic of asthma-induced lung pathology [12,28-30]. As both human and mouse OSM are able to upregulate the expression of MCP-1 by fibroblasts, it has been suggested that OSM is involved in the pathogenesis of eosinophilic pneumonia, associated with increased levels of MCP-1 in BAL fluid [12]. Our finding that OSM induces CCL28 from epithelial cells may mean that some of these effects are mediated in part through CCL28 and that the epithelium may contribute to these processes. Although the role of eosinophils in asthma has attracted some debate, emerging data from murine models suggest that eosinophils play a central role in the early events of asthma induction including remodelling and hyperresponsiveness $[13,17,18]$. Given that eosinophils express the CCR3 receptor [31], our finding of abundant CCL28 in airway
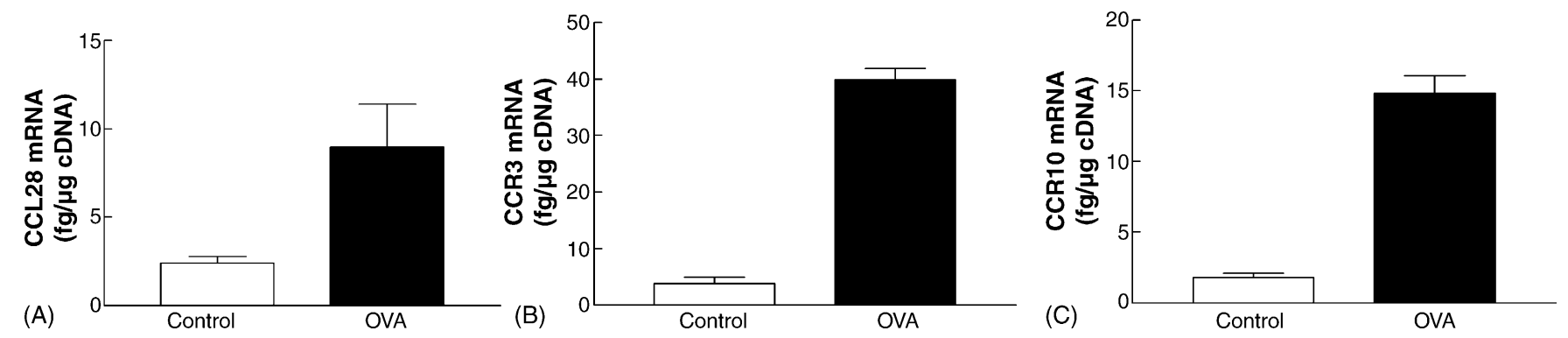

Fig. 5. CCL28 and CCR 10 mRNA are upregulated in the airways of OVA sensitized mice. Levels of CCL28, CCR3 and CCR10 mRNA were determined by quantitative real time PCR from lung tissue isolated as descried in Section 2.5. Results shown are mean ( \pm S.E.M.) of three determinations from a representative experiment performed at least three times. Statistical significance from unstimulated control, $p<0.005$. 

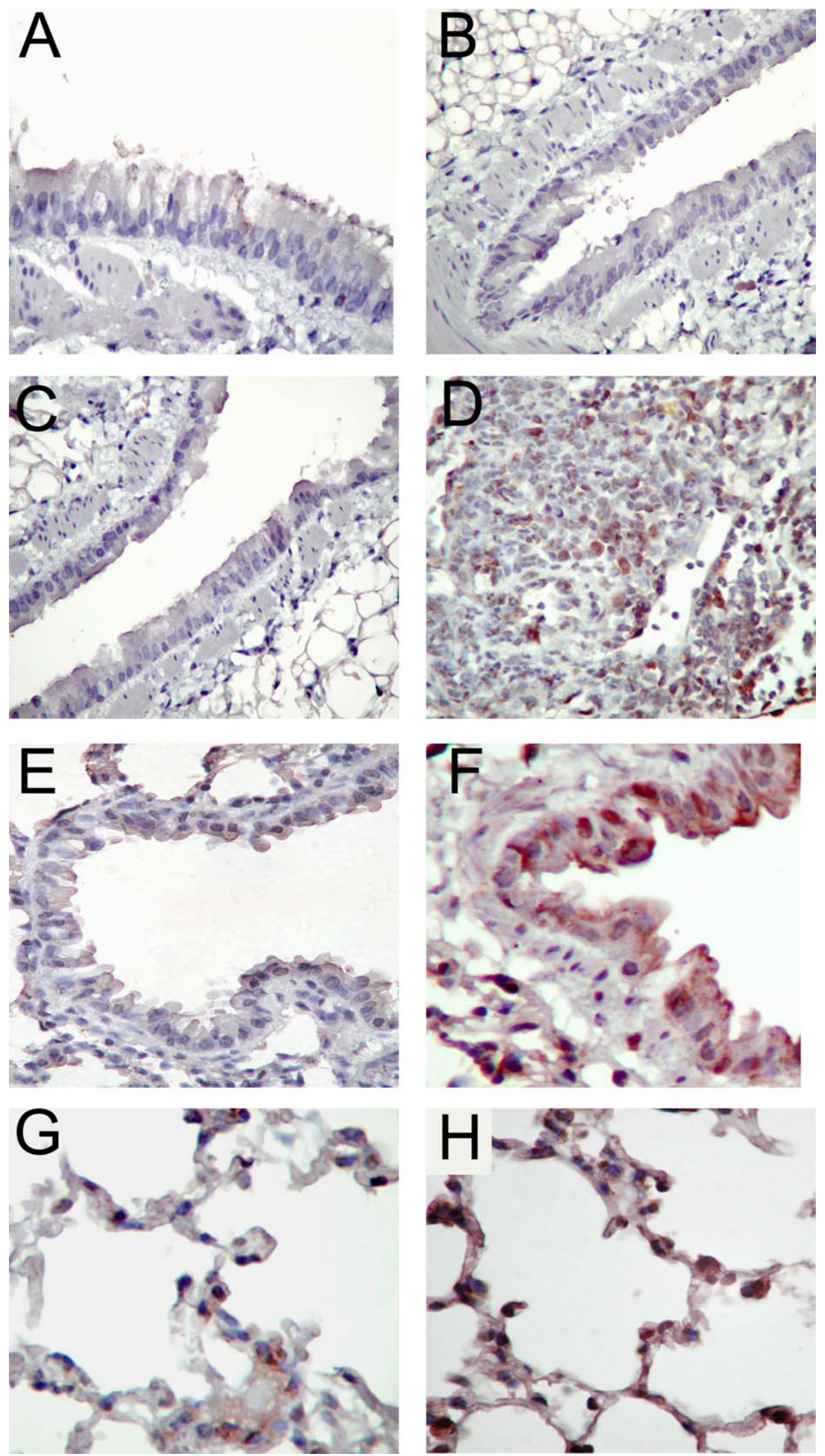

Fig. 6. CCR10 expressing cells can be detected in the airways of OVA sensitized mice. Mice ( $n=8$ per group) were either sensitized to OVA (A, B, D, F and H) or sham sensitized with endotoxin-free PBS (C, E and G). Lung sections were assayed using an irrelevant polyclonal rabbit serum (A), pre-immune rabbit serum (B) or an affinity purified rabbit anti-mouse CCR10 serum $(\mathrm{C}-\mathrm{H})$. All sections were probed using biotinylated goat anti-rabbit IgG, streptavidin conjugated horse radish peroxidase using $3,3^{\prime}$-diaminobenzidine tetrahydrochloride as substrate. Sections were counterstained with haematoxylin. Original magnification $\times 400$ (A-D) or $\times 800(\mathrm{E}-\mathrm{H})$. 
epithelium associated with an eosinophil influx indicates that CCL28 may contribute to eosinophil recruitment to the airway and in the pathology associated with allergic inflammation.

Recent work by John et al. [14] has demonstrated that CCL28 is upregulated in another murine model of airway hyperresponsiveness. Using a different model (OVA) and reagents, we validate that work and show CCL28 expression in a murine model of allergic inflammation. However in contrast to that study, we observed elevated expression of CCR10 protein and mRNA after allergen challenge of senstitised airways. This receptor has not previously been implicated in leukocyte homing in models of airway hyper-responsiveness and its detection in sensitized airways provides at least circumstantial evidence consistent with CCL28 playing a role in airway inflammation, consistent with other studies of CCR10 in vitro or at other mucosal sites $[2,5,19]$. However, it would be premature to conclude from the approaches in the present study that CCR10 is the principal receptor involved in this interaction. To date, very little data is known about CCR10 and its potential role in mucosal inflammation [2,5,19], a full understanding of that function in the airways awaits the development of new reagents and knockout mice.

Nevertheless, our findings show that inflammatory mediators from different classes can induce CCL28 from airway cells and that CCL28 is upregulated in a well-characterised model of airway hyper-responsiveness. We provide the first observations suggesting that CCR10 is elevated in airway inflammation. Taken together, these findings support the suggestion that therapeutic intervention targeting this chemokine [14], or factors such as OSM that are involved in induction of high level CCL28 expression by epithelial cells, may be beneficial in relieving allergic airway inflammation.

\section{Acknowledgments}

This work was supported by funding from the Irish Health Research Board (Basic research grant scheme), Bernard Mahon is a Wellcome Trust "New Blood" fellow (GR054236).

\section{References}

[1] Pan J, Kunkel EJ, Gosslar U, Lazarus N, Langdon P, Broadwell K, et al. Cutting edge: a novel chemokine ligand for CCR10 and CCR3 expressed by epithelial cells in mucosal tissues. J Immunol 2000;165:2943-9.

[2] Wang W, Soto H, Oldham ER, Buchanan ME, Homey B, Catron D, et al. Identification of a novel chemokine (CCL28), which binds CCR10 (GPR2). J Biol Chem 2000;275:22313-23.

[3] Hieshima K, Kawasaki Y, Hanamoto H, Nakayama T, Nagakubo D, Kanamaru A, et al. CC chemokine ligands 25 and 28 play essential roles in intestinal extravasation of $\operatorname{IgA}$ antibody-secreting cells. J Immunol 2004;173:3668-75.

[4] Bourges D, Wang CH, Chevaleyre C, Salmon H, IgA T. B lymphocytes of the pharyngeal and palatine tonsils: differential expression of adhesion molecules and chemokines. Scand J Immunol 2004;60:338-50.

[5] Wilson E, Butcher EC. CCL28 controls immunoglobulin (Ig)A plasma cell accumulation in the lactating mammary gland and $\operatorname{IgA}$ antibody transfer to the neonate. J Exp Med 2004;200:805-9.

[6] Hieshima K, Ohtani H, Shibano M, Izawa D, Nakayama T, Kawasaki Y, et al. CCL28 has dual roles in mucosal immunity as a chemokine with broad-spectrum antimicrobial activity. J Immunol 2003;170:1452-61.
[7] Holgate ST, Davies DE, Lackie PM, Wilson SJ, Puddicombe SM, Lordan JL. Epithelial-mesenchymal interactions in the pathogenesis of asthma. J Allergy Clin Immunol 2000;105:193-204.

[8] Ennis DP, Cassidy JP, Mahon BP. Prior Bordetella pertussis infection modulates allergen priming and the severity of airway pathology in a murine model of allergic asthma. Clin Exp Allergy 2004;34:148897.

[9] Mathew A, Medoff BD, Carafone AD, Luster AD. Cutting edge: Th2 cell trafficking into the allergic lung is dependent on chemoattractant receptor signaling. J Immunol 2002;169:651-5.

[10] Ackerman V, Marini M, Vittori E, Bellini A, Vassali G, Mattoli S. Detection of cytokines and their cell sources in bronchial biopsy specimens from asthmatic patients. Relationship to atopic status, symptoms, and level of airway hyperresponsiveness. Chest 1994;105:687-96.

[11] Homey B, Dieu-Nosjean MC, Wiesenborn A, Massacrier C, Pin JJ, Oldham E, et al. Up-regulation of macrophage inflammatory protein$3 \mathrm{alpha/CCL20}$ and CC chemokine receptor 6 in psoriasis. J Immunol 2000;164:6621-32.

[12] Langdon C, Kerr C, Tong L, Richards CD. Oncostatin M regulates eotaxin expression in fibroblasts and eosinophilic inflammation in C57BL/6 mice. J Immunol 2003;170:548-55.

[13] Hanamoto H, Nakayama T, Miyazato H, Takegawa S, Hieshima K, Tatsumi Y, et al. Expression of CCL28 by Reed-Sternberg cells defines a major subtype of classical Hodgkin's disease with frequent infiltration of eosinophils and/or plasma cells. Am J Pathol 2004;164:9971006.

[14] John AE, Thomas MS, Berlin AA, Lukacs NW. Temporal production of CCL28 corresponds to eosinophil accumulation and airway hyperreactivity in allergic airway inflammation. Am J Pathol 2005;166:34553.

[15] Ying S, Meng Q, Zeibecoglou K, Robinson DS, Macfarlane A, Humbert $\mathrm{M}$, et al. Eosinophil chemotactic chemokines (eotaxin, eotaxin-2, RANTES, monocyte chemoattractant protein-3 (MCP-3), and MCP4), and C-C chemokine receptor 3 expression in bronchial biopsies from atopic and nonatopic (Intrinsic) asthmatics. J Immunol 1999;163: 6321-9.

[16] Romagnani S. Cytokines and chemoattractants in allergic inflammation. Mol Immunol 2002;38:881-5.

[17] Lee JJ, Dimina D, Macias MP, Ochkur SI, McGarry MP, O'Neill KR, et al. Defining a link with asthma in mice congenitally deficient in eosinophils. Science 2004;305:1773-6.

[18] Humbles AA, Lloyd CM, McMillan SJ, Friend DS, Xanthou G, McKenna EE, et al. A critical role for eosinophils in allergic airways remodeling. Science 2004;305:1776-9.

[19] Kunkel EJ, Kim CH, Lazarus NH, Vierra MA, Soler D, Bowman EP, et al. CCR10 expression is a common feature of circulating and mucosal epithelial tissue IgA Ab-secreting cells. J Clin Invest 2003;111:100110.

[20] Ennis DP, Cassidy JP, Mahon BP. Whole-cell pertussis vaccine protects against Bordetella pertussis exacerbation of allergic asthma. Immunol Lett 2005;97:91-100.

[21] Ennis DP, Cassidy JP, Mahon BP. Acellular pertussis vaccine protects against exacerbation of allergic asthma due to Bordetella pertussis in a murine model. Clin Diagn Lab Immunol 2005;12:409-17.

[22] Lazarus NH, Kunkel EJ, Johnston B, Wilson E, Youngman KR, Butcher EC. A common mucosal chemokine (mucosae-associated epithelial chemokine/CCL28) selectively attracts IgA plasmablasts. J Immunol 2003;170:3799-805.

[23] Ma W, Bryce PJ, Humbles AA, Laouini D, Yalcindag A, Alenius H, et al. CCR3 is essential for skin eosinophilia and airway hyperresponsiveness in a murine model of allergic skin inflammation. J Clin Invest 2002;109:621-8.

[24] Stahl N, Boulton TG, Farruggella T, Ip NY, Davis S, Witthuhn BA, et al. Association and activation of Jak-Tyk kinases by CNTF-LIF-OSM-IL-6 beta receptor components. Science 1994;263:92-5.

[25] Hakonarson H, Halapi E, Whelan R, Gulcher J, Stefansson K, Grunstein MM. Association between IL-1beta/TNF-alpha-induced glucocorticoidsensitive changes in multiple gene expression and altered responsiveness 
in airway smooth muscle. Am J Respir Cell Mol Biol 2001;25:76171.

[26] Liu AH. Endotoxin exposure in allergy and asthma: reconciling a paradox. J Allergy Clin Immunol 2002;109:379-92.

[27] O'Neill LA. Signal transduction pathways activated by the IL-1 receptor/toll-like receptor superfamily. Curr Top Microbiol Immunol 2002;270:47-61.

[28] Langdon C, Leith J, Smith F, Richards CD. Oncostatin M stimulates monocyte chemoattractant protein-1- and interleukin-1-induced matrix metalloproteinase-1 production by human synovial fibroblasts in vitro. Arthritis Rheum 1997;40:2139-46.
[29] Grove RI, Eberhardt C, Abid S, Mazzucco C, Liu J, Kiener P, et al. Oncostatin $\mathrm{M}$ is a mitogen for rabbit vascular smooth muscle cells. Proc Natl Acad Sci USA 1993;90:823-7.

[30] Li WQ, Dehnade F, Zafarullah M. Oncostatin M-induced matrix metalloproteinase and tissue inhibitor of metalloproteinase-3 genes expression in chondrocytes requires Janus kinase/STAT signaling pathway. J Immunol 2001;166:3491-8.

[31] Stellato C, Brummet ME, Plitt JR, Shahabuddin S, Baroody FM, Liu $\mathrm{MC}$, et al. Expression of the C-C chemokine receptor CCR3 in human airway epithelial cells. J Immunol 2001;166:1457-61. 